\title{
CONSIDERAÇÕES DE ARENDT SOBRE O CONCEITO DE VONTADE GERAL DE ROUSSEAU
}

\author{
ARENDT'S CONSIDERATIONS ON THE CONCEPT OF ROUSSEAU'S GENERAL WILL
}

\author{
José João Neves Barbosa Vicente*
}

\begin{abstract}
RESUMO
A vontade geral é um conceito fundamental no pensamento político de Rousseau; é através desse conceito que Rousseau pensa a comunidade política "legítima", como descrita em Do contrato social, em que a liberdade de cada indivíduo é protegida e preservada. Arendt, no entanto, não compartilha dessa ideia e considera o conceito de vontade geral como descrito por Rousseau uma ameaça à política; ele a enfraquece e a destrói, uma vez que não permite a manifestação da liberdade através de ação e do debate de opiniões entre iguais. Não se pode admitir e nem aceitar ideias ou práticas políticas que tentam homogeneizar as formas de vida humana, que tentam excluir ou controlar a diversidade de opiniões. Defender a ideia de um povo homogêneo que compartilha de uma vontade geral como descrita em Do contrato social, não significa fortalecer a política, mas sim atentar contra a pluralidade humana que dá sentido à comunidade política. A proposta do presente artigo é discutir o posicionamento crítico de Arendt em relação ao conceito de vontade geral de Rousseau

PALAVRAS- CHAVE: Vontade geral. Rousseau. Pluralidade humana. Liberdade. Arendt.
\end{abstract}

\begin{abstract}
The general will is a fundamental concept in Rousseau's political thinking; It is through this concept that Rousseau thinks the "legitimate" political community, where each individual's freedom is protected and preserved. Arendt, however, does not share this idea and considers the concept of general will as described by Rousseau, a threat to politics; it weakens and destroys it, since it does not allow the manifestation of freedom through action and the debate of opinions between equals. Political ideas and practices that attempt to homogenize human life forms that try to exclude or control diversity of opinion can not be accepted or accepted. Defending the idea of a homogenous people that shares a general will as described in The social contract does not mean to strengthen politics, but to attack the human plurality that gives meaning to the political community. The proposal of this article is to discuss this critical positioning of Arendt in relation to the concept of general will of Rousseau.
\end{abstract}

KEYWORDS: General will. Rousseau. Human plurality. Freedom.Arendt.

A vontade geral é indubitavelmente um conceito imprescindível no pensamento político de Rousseau; sem ele, o pensador genebrino não teria elementos suficientes para pensar a comunidade política "legítima" como descrita em Do contrato social ${ }^{1}$. Na verdade,

\footnotetext{
Professor de Filosofia da Universidade Federal do Recôncavo da Bahia (UFRB). E-mail: josebvicente@bol.com.br.

${ }^{1}$ Diferente dos pensadores anteriores, inclusive Montesquieu a quem ele "admira" e "muito deve" Rousseau em Do contrato social, não desenvolve um projeto de "essência histórica", ou seja, ele não se debruça sobre a "gênese do Estado", não discute "fatos", não visa "explicar as instituições políticas"; sua grande preocupação é dizer o que é uma comunidade
} 
para Rousseau, a comunidade política dirigida pela vontade geral é a única capaz não apenas de preservar, mas também de proteger a liberdade de cada indivíduo como parte constitutiva do seu ser. A vontade geral, portanto, como entendida e descrita por Rousseau, é essencial para garantir uma sociedade politicamente organizada, em que cada um dos seus membros obedece apenas a si mesmo, permanecendo assim livre.

Para Arendt, no entanto, o conceito de vontade geral que funciona como o coração da obra Do contrato social de Rousseau, não contribui para o fortalecimento da política, na verdade, ele a enfraquece e a destrói, uma vez que não permite a manifestação da liberdade através de ação e do debate de opiniões entre iguais. Não se pode admitir e nem aceitar ideias ou práticas políticas que tentam homogeneizar as formas de vida humana, que tentam excluir ou controlar a diversidade de opiniões: "O mundo comum”, afirma Arendt (2009a, p. 68), "acaba quando é visto somente sob um aspecto e só se lhe permite uma perspectiva".

Defender a ideia de um povo homogêneo que compartilha de uma vontade geral como descrita em Do contrato social não significa fortalecer a política, mas sim atentar contra a pluralidade humana que dá sentido à comunidade política; para Arendt, a liberdade não pode ser identificada com um ato de vontade e nem pertence a um sujeito singular ou coletivo. $\mathrm{Na}$ visão de Arendt, uma comunidade política baseada na vontade geral, como pensada por Rousseau, "nega a base da liberdade humana, ou seja, a capacidade das pessoas para compartilhar seus diversos pontos de vista" (GARDINER, 2015, p. 34). De acordo com o pensamento político de Arendt, a liberdade não se manifesta na ausência de interação e relação plural entre os homens; ela jamais se manifesta, por exemplo, na submissão a uma vontade, como acredita Rousseau, mas sim na ação conjunta de seres plurais em um espaço público.

A ideia de uma vontade geral descrita por Rousseau como alternativa para defender a liberdade dos indivíduos é, para Arendt, um equívoco e um perigo para a política como é, também, todo tipo de pensamento que não leva em consideração a pluralidade humana, a diversidade de opiniões e os debates públicos como condições de toda e qualquer política. Arendt, como observou Lafer (1988, p. 229), “afirma a importância da diversidade e exprime

política, para que "o poder" por ela exercido "seja legítimo" (HUISMAN, 2000, p. 86). Assim, o contrato pensado por ele para criar uma comunidade política legítima na qual os homens jamais perderiam sua liberdade é, também, em larga medida, diferente dos contratos pensados pelos pensadores como Hobbes, que colocou "a doutrina do contrato a serviço da defesa do poder absoluto" e Locke, que a "usou para defender a revolução liberar inglesa de 1688". Em épocas posteriores, Kant se aproximou da ideia rousseauniana de contrato ao defini-lo como "o ato pelo qual o próprio povo se constrói em um Estado"”, enquanto Hegel rejeita a teoria contratualista de formação de Estado (ABBAGNANO, 2007, p. 206). Para Rousseau, na comunidade política formada pelo contrato, o povo dirigido pela vontade geral é o único soberano; e como autor de suas próprias leis, ele é livre. 
o horror ao 'um' da soberania e da vontade geral". Para Arendt, os indivíduos não têm que se unir em torno de uma "vontade geral"; o que deve uni-los é o mundo comum e a vontade de criar um espaço político em que suas diferenças possam ser articuladas, contestadas e resolvidas por meio da ação e do discurso. Ao contrário da visão coletivista de uma cidadania unida dentro da "vontade geral" defendida por Rousseau, na qual a política se reduz à política do silêncio, Arendt enfatiza a pluralidade humana porque para ela, se as coisas "chegarem ao ponto em que todos vejam e entendam tudo a partir da mesma perspectiva, vivendo em total unanimidade, o mundo terá chegado ao seu fim no sentido histórico-político" (ARENDT, 2009b, p. 238).

A vontade geral indivisível e voltada para a unanimidade é, para Arendt, uma ameaça à política, jamais a sua salvação. Totalmente desvinculada da "necessidade de discutir com os outros no espaço público", a vontade geral de Rousseau surge como "uma força não política ou até mesmo antipolítica" (LA CAZE, 2014, p. 218). Para Arendt, a "vontade geral" expressa a vontade do povo apenas como uma entidade singular, uma vez que o concebe como uma "personalidade policéfala", ou em outras palavras, como um "monstro de muitas cabeças, uma massa que se move com um só corpo e age como se possuída de uma única vontade" (ARENDT, 1988, p. 74-75). Em sua essência, a vontade geral representa, portanto, uma forma engenhosa de colocar uma multidão no lugar de uma única pessoa, afinal, ela não é outra coisa senão o elo que aglutina todos num só corpo. A "metáfora de uma vontade geral" foi tomada "tão a sério e tão literalmente" por Rousseau, que ele "chegou a conceber a nação como um corpo animado por uma só vontade", cuja qualidade mais notável é a sua "unanimidade". Para ele, portanto, "a unidade permanente do futuro corpo político não era garantida pelas instituições temporais, mas pela vontade do povo", e não é de se estranhar, por exemplo, que quando Robespierre "se referia à 'opinião pública', ele queria dizer a unanimidade da vontade geral", ele nunca pensou, em nenhum momento, "em uma opinião sobre a qual a maioria estivesse de acordo" (ARENDT, 1988, p. 61).

A grande preocupação dos revolucionários franceses que se inspiraram na teoria política de Rousseau elaborada em sua obra Do contrato social, e que pretendiam arrancar da face da sociedade "a máscara da hipocrisia", expor toda a sua "podridão", eliminar de uma vez por todas a sua "fachada de corrupção" para celebrar, finalmente, a "honesta e impoluta face do peuple", não era outra coisa senão como encontrar um meio de unir o povo francês, ou em outras palavras, "como 'fazer com que 25 milhões de franceses, que nunca tinham conhecido ou imaginado alguma lei que não fosse a vontade do rei, se congregassem em torno 
de qualquer constituição livre"” (ARENDT, 1988, p. 61). Eles insistiram, portanto, na unidade nacional, principalmente devido à influência da ideia da vontade geral de Rousseau, enquanto os revolucionários americanos usaram "a palavra povo" que, para eles, não era um corpo constituído de indivíduos abstratos, mas sim uma multiplicidade de vozes e interesses; povo tinha, portanto, para eles, "o sentido de coletividade, de infindável variedade de uma multidão cuja majestade residia em sua própria pluralidade" (ARENDT, 1988, p. 74). A ideia rousseauniana de uma vontade geral soberana "inspirando e dirigindo a nação, como se ela não fosse mais formada de uma multidão, mas de uma só pessoa", sublinha Arendt (1988, p. 125), “tornara-se axiomática para todas as facções e partidos da Revolução Francesa, por ser ela, na verdade, o substituto teórico da vontade soberana de um monarca absoluto".

Para Arendt, Rousseau se esqueceu de que as pessoas não permanecem politicamente unidas através da submissão a uma vontade, mas sim por meio de trocas de opiniões. A vontade geral como pensada por ele não protege o verdadeiro espírito público, é uma afronta à pluralidade humana, condição de toda a vida política; na verdade, como observou Esposito (2006, p. 121), na "vontade geral" de Rousseau a pluralidade humana encontra-se totalmente “dominada pela unidade”. Para Arendt, não existe liberdade ou participação política efetiva sem a opinião dos indivíduos que se forma num processo de discussão aberta e de debate público; divergências e diferenças não podem ser tomadas como algo pernicioso para a atividade política, mas como um elemento que contribui para garantir a sua existência. $\mathrm{O}$ “contrato" imaginado por Rousseau, como destacou Amiel (2003, p. 70-71), só pode criar uma comunidade política "fundada em areias movediças", pois ele foi "concebido como um contrato entre mim e eu mesmo" e, em essência, ele exclui "a própria possibilidade da formação de opinião". Para Arendt, portanto, observa Canovan (1992, p. 226), apesar de Rousseau ter intitulado a sua obra Do contrato social, "a ênfase colocada sobre a soberania da vontade mostra que ele nunca tinha realmente pensado sobre o que um contrato é".

Nessa mesma linha de interpretação, Forti (2001, p. 205-206) sublinha que, para Arendt, a obra Do contrato social de Rousseau "contém uma contradição que não pode ser resolvida". Essa contradição reside, fundamentalmente, na "incompatibilidade entre contrato e omnipotência da vontade". Rousseau não leva em consideração, por exemplo, os laços e obrigações que fazem parte de todo e qualquer contrato, e que servem como remédios à possibilidade de amanhã o indivíduo não querer mais o que ele queria no momento do contrato. Por outro lado, Rousseau parece ter se esquecido, também, que "toda a teoria contratual reside na ideia de consenso" com seus significados implícitos de escolha deliberada 
e consulta de opinião. Em sua teoria política, essa ideia encontra-se substituída pelo conceito de "vontade que, substancialmente, exclui todo o processo de troca de opiniões e toda tentativa de conciliar diversas opiniões", afinal, para ele, "uma vontade dividida seria inconcebível: não há mediação possível entre diversas vontades como, por exemplo, existe entre ‘diversas opiniões"”. A vontade como concebida por Rousseau, é "uma vontade de unidade" e, nesse sentido, representa uma oposição radical à pluralidade.

Ainda é preciso destacar que a durabilidade dos vínculos sociais, para Arendt, não se funda sobre interesse geral ou sobre a vontade soberana, mas sobre promessas que, como disse Thomas (1997, p. 287), não significa "a fusão de vontades autônomas em Rousseau, como a vontade geral", mas sim "uma atividade que permite às pessoas 'agir em concerto' sem apagar a pluralidade". A promessa é uma das características importantes do pensamento político de Arendt, pois para ela, o futuro é imprevisível e incerto, os homens “jamais podem garantir hoje quem serão amanhã", e ninguém é capaz de "prever as consequências de um ato numa comunidade de iguais, onde todos têm a mesma capacidade de agir", sendo assim, a capacidade de prometer e de cumprir promessas serve para "aclarar" a "obscuridade dos negócios humanos"; nesse sentido, ela é, portanto, para a autora, "a única alternativa a uma supremacia baseada no domínio de si mesmo e no governo de outros". A capacidade de prometer e de cumprir promessas "corresponde exatamente à existência de uma liberdade que é dada sob a condição de não-soberania", ela pode ser descrita como "pequenas ilhas de certeza num oceano de incertezas" (ARENDT, 2009a, p. 255-256).

Portanto, uma vez que o futuro, por definição, é "um oceano de incertezas", a promessa tem a função de criar "certas ilhas de segurança, sem as quais não haveria continuidade, e menos ainda durabilidade de qualquer espécie, nas relações entre os homens" (ARENDT, 2009a, p. 249). Por isso, como disse Müller (2013, p. 37-38), a promessa, como entendida por Arendt, "pode ser compreendida como o compromisso do cidadão em relação ao mundo", um compromisso que "consiste no dever de manter a promessa feita [...], pois quando se promete objetiva-se cumprir o prometido", nesse sentido, um "bom cidadão é aquele que possui o 'espírito' público, que tem compromisso com a república - com a coisa pública - e com o bem comum". A promessa é, assim, dependente da condição da pluralidade humana, ou seja, ela só faz sentido na presença de outros indivíduos; na "solidão e no isolamento", afirma Arendt (2009a, p. 249), ela não tem qualquer "realidade", é apenas "um papel que a pessoa encena para si mesma”, e sem ela, é praticamente impossível qualquer durabilidade ou estabilidade dos vínculos sociais. 
Os ensinamentos políticos de Rousseau baseados na ideia de uma vontade geral soberana, como sublinhou Arendt (1988, p. 193), reclamam "a union sacrée, a eliminação de todas as diferenças e distinções". Nesse sentido, eles são tentativas de constituir uma singularidade a partir de uma pluralidade ou, em outras palavras, são tentativas de reunir uma multidão em um só corpo, capaz de desintegrar a pluralidade e a multiplicidade dentro do espaço da aparência que são necessárias à vida política autêntica. Assim, os homens se tornam "seres inteiramente privados", isto é, "privados de ver e ouvir os outros e privados de ser vistos e ouvidos por eles. São todos prisioneiros da subjetividade de sua própria existência singular" (ARENDT, 2009a, p. 67-68). A vontade geral de Rousseau é, portanto, radicalmente contra a pluralidade humana, uma que ela é por natureza una e indivisível, o que significa dizer que o corpo político é igualmente uno e indivisível. Mas, para Arendt, a unidade ou a homogeneidade, como disse Abreu (2007, p. 191), "não é algo a ser buscado", mas "é algo a ser combatido", pois ela "era uma das características atribuídas ao povo pelos governos totalitários”. Os cidadãos, para Arendt, afirma Canovan (1992, p. 226), mantêm-se juntos "não por uma vontade comum, mas por um mundo comum".

Para Arendt, uma comunidade política é, precisamente, uma comunidade sem unidade, pois a pré-condição para o mundo político é a pluralidade, não a vontade geral. Ou ainda, como disse Villa (2008, p. 352), a comunidade política "é uma associação de diversos iguais" cujo cuidado compartilhado para com o mundo público assume a forma de debate aberto, deliberações e decisões; nesses debates e decisões políticas, o que está em jogo "é a melhor maneira de 'preservar e aumentar' o espaço de liberdade pública”. A teoria política desenvolvida por Rousseau ao longo da sua obra Do contrato social é, para Arendt, toda ela apoiada "na curiosa equivalência entre vontade e interesse", e a "sua presunção tácita é que a vontade é alguma espécie de articulação automática de interesse"; nesse sentido, a "vontade geral é a articulação de um interesse geral, o interesse do povo ou da nação como um todo" mas, por ser geral, a existência desse interesse ou vontade possui realidade apenas "na oposição a cada interesse ou vontade particular” (ARENDT, 1988, p. 62).

Para Arendt, Rousseau criou, nesse sentido, as bases para que todos aqueles que acreditam na "vontade geral", possam hostilizar os interesses particulares dos cidadãos como sendo inimigos da nação. Não foi por acaso, por exemplo, que a Revolução Francesa, bem como todas as outras revoluções que se inspiraram na "vontade geral", observa Arendt (1988, p. 63), partiram do princípio de que "o interesse de todos deve automaticamente, e de certo permanentemente, ser hostil ao interesse particular do cidadão". Todos estavam convictos de 
que "o valor de uma política" se mede, exclusivamente, "pela intensidade com que ela se opõe a todos os interesses particulares", e o valor de cada homem se avalia, unicamente, "pelo empenho com que age contra seu próprio interesse e contra sua própria vontade”. Para a autora, portanto, na teoria política de Rousseau, o inimigo externo que fortalece o nó social transfigura-se em inimigo interno, isto é, a interioridade de cada cidadão; o "problema" de Rousseau "era onde descobrir um inimigo comum fora do âmbito das relações exteriores, e sua solução foi que tal inimigo existia no íntimo de cada cidadão, isto é, em sua vontade e interesse particular” (ARENDT, 1988, p. 62). Assim, para participar da vida política, o cidadão precisa rebelar incessantemente contra si mesmo.

A vontade geral de Rousseau, afirma Arendt (1988, p. 60), "exclui todos os processos de troca de opiniões e um eventual acordo entre elas". Por isso, disse Forti (2001, p. 206), para a autora, "é um verdadeiro 'absurdo teórico"” pretender "fundar o espaço público" sobre tal vontade. Incapaz de lidar com a pluralidade humana, com a diversidade dos indivíduos, o pensamento político de Rousseau, como sublinhou Charvert (1974, p. 145), faz uma "abolição sistemática dos outros" e propõe uma comunidade política que nada mais é senão um espaço onde cada cidadão só opine de acordo consigo mesmo. A maneira como Rousseau pensa a comunidade política é extremamente perigosa, pois um "Estado onde não existe comunicação entre os cidadãos e onde cada homem pensa apenas seus próprios pensamentos é, por definição, uma tirania" (ARENDT, 1972, p. 212). Nenhum homem é dono ou mestre das suas ações quando se respeita ou se considera a pluralidade humana; por isso, mais do que uma ilusão, a vontade geral soberana de Rousseau deve ser considerada, também, um conceito totalmente alheio à ação política.

Rousseau, na verdade, de acordo com Arendt, ao introduzir o seu conceito de vontade geral na política, ele nega aos homens a oportunidade de serem livres, uma vez que em sua essência, o conceito de vontade geral fecha totalmente toda a possibilidade de se exercer uma discussão livre ou debater e trocar opiniões entre os cidadãos. Nesse sentido, a vontade geral surge como uma forte recusa da "condição humana da pluralidade" que se encontra alicerçada no fato de que a "terra" não é um ambiente habitado pelo "Homem", mas sim pelos "homens", e se esses homens forem unidos em torno de uma única vontade que passará a guiá-los em uma comunidade política, nenhum deles poderá ser livre. O conceito de vontade geral de Rousseau é, portanto, extremamente perigoso para a esfera política, pois dizer que ser livre é ser totalmente independente significa negar a possibilidade da liberdade que, como afirmou Parekh (2008, p. 115), se manifesta na ação e é "radicalmente interdependente". A 
"liberdade requer pluralidade humana", pois "a ação requer pessoas que trabalham em conjunto e não no isolamento". Para Arendt, é necessário agir com outras pessoas, por isso sua concepção de liberdade encontra-se alicerçada no convívio humano e não na vontade, seja a minha, de uma outra pessoa ou de um grupo. A autora faz, assim, um alerta contra a assimilação da liberdade com a vontade, pois para ela isso implica equiparar liberdade com a soberania, e "no campo das atividades humanas", afirma Arendt (1988, p. 123), "soberania e tirania são a mesma coisa".

Para Arendt (2009a, p. 246), a soberania, esse "ideal da inflexível autossuficiência e autodomínio", ou em outras palavras, "esse ideal de um livre arbítrio, independente dos outros e eventualmente prevalecendo sobre eles" (ARENDT, 1972, p. 211), não é a mesma coisa que a liberdade como acredita Rousseau, "o representante mais coerente da teoria da soberania, derivada por ele diretamente da vontade, de modo a poder conceber o poder político à imagem estrita da força de vontade individual" (ARENDT, 1972, p. 211-212). Na verdade, em termos arendtianos, "se a soberania e a liberdade fossem a mesma coisa", como admite Rousseau em seus estudos sobre a política, "nenhum homem poderia ser livre", pois onde a soberania impera, a pluralidade ou a condição da liberdade e de "toda a vida política" encontra-se ausente ou destruída; a soberania, portanto, “contradiz a própria condição humana da pluralidade" (ARENDT, 2009a, p. 246). A liberdade, para Arendt, não consiste no controle da ação, mas na própria ação, ela não é, portanto, “um atributo da vontade, mas sim um acessório do fazer e do agir" (ARENDT, 1972, p. 213), e enquanto a Terra for um lugar habitado por homens e não Homem, nenhum deles pode viver sozinho e nem pode existir como um indivíduo soberano.

Arendt ressalta, ainda, que "nos sistemas politeístas, por exemplo, nem mesmo um "deus", por mais poderoso que seja, pode ser soberano", a ideia de "soberano" surge "somente quando se pressupõe um deus único (“Um é um e só e sempre o será”)", e apenas nessa condição, também, "pode a soberania equivaler a liberdade" (ARENDT, 2009a, p. 246). A ideia de soberania, portanto, para Arendt, não passa de uma tentativa de controlar a existência da pluralidade, que é a pré-condição da liberdade, e essa tentativa que aparece de forma determinante na teoria política desenvolvida por Rousseau em sua obra Do contrato social, tem a sua origem no pensamento político de Platão. Para esse pensador, a legitimidade do governo consiste no "autodomínio", seus "princípios orientadores" são buscados "na relação que a pessoa mantém consigo mesma" e, nesse sentido, as questões referentes ao "certo" e ao "errado" nas relações com outras pessoas são determinadas "pelas atitudes que ela assume em 
relação a si própria, até que toda a esfera pública", por assim dizer, "passa a ser vista à imagem do 'homem escrito em maiúsculas', da ordem adequada entre cada uma das capacidades da alma, do corpo e da mente do homem” (ARENDT, 2009a, p. 249). A grande verdade, no entanto, é que, para Arendt, como afirmou Dossa (1989, p. 85), "a essência da liberdade é que ela proíbe soberania a um indivíduo ou a um grupo", e a autora "está convencida que no domínio dos assuntos humanos, em 'qualquer circunstância, soberania só é possível apenas na imaginação"”.

Diferente de Rousseau, Arendt não está preocupada com a unidade, mas com a interrelação. Por isso, como destacou Herb (2002, p. 78), "a fundamentação contratualista" de Rousseau é, para ela, "um absurdo", pois nem o "indivíduo" e nem a "república” devem ser compreendidos "como unidade autárquica e hermética"; nesse sentido, só riscando "o singular da gramática do republicanismo" é possível traçar "as origens do político". Para Arendt, a liberdade e a participação política efetiva dos cidadãos não acontecem em uma comunidade política constituída por um povo soberano guiado pela vontade geral, mas em um governo capaz de proporcionar aos homens espaços onde todos possam aparecer através da ação em conjunto, uma forma de governo que funciona como "uma espécie de anfiteatro" onde a liberdade de cada cidadão possa aparecer. Para a autora, portanto, não existe nenhuma razão para que o agir político com os outros envolva uma "vontade geral" una e indivisível, pois o ponto de vista geral é construído por uma pluralidade de pontos de vista que juntos constituem um mundo comum.

Para Arendt, a verdadeira república não existe sem a participação ativa dos cidadãos através da ação e do discurso, e onde a pluralidade humana, como disse Topolski (2015, p. 63), é reduzida a "uma vontade singular e indivisível”, os homens encontram-se mais perto da tirania do que da liberdade. Sem a pluralidade é praticamente impossível qualquer atividade especificamente humana, nem mesmo a atividade de pensar é possível, "eu quando estou comigo mesmo (= pensar)", afirma Arendt (2002, p. 192), "sou dois e não um. A pluralidade penetra o estar só". Nas palavras de Birulés (2007, p. 206), isso significa adentrar "naquilo que Paul Ricoeur denominou o 'cogito plural': só poderíamos escapar da pluralidade deixando de pensar, deixando de nos relacionar com nós mesmos". Para Arendt, portanto, observa Lobo (2013, p. 149), "não há mundo sem a pluralidade humana, ou pluralidade humana sem mundo; finalmente, não há homens sem mundo ou pluralidade", e se ela discorda da forma como Rousseau defende a liberdade dos cidadãos, é porque em Rousseau, como afirmou Forti (2001, p. 203), a política "obriga" os indivíduos a "uma identificação total com 
um corpo político no qual se anulam diferenças e distinções”, o sujeito desse corpo político é "uma vontade geral que na realidade 'se comporta como o mais solitário dos homens"”.

Nas palavras de Nihan (2011, p. 224), Arendt reprova em Rousseau o seu "incentivo" para que o indivíduo silencie a "pluralidade que atravessa sua identidade", pois quando o indivíduo se submete à "vontade geral", ele nega “o caráter plural da sua própria subjetividade". Como disse Villa (1996, p. 76), Arendt se opõe de forma radical à "política de autenticidade inventada por Rousseau", ela recusa "a moderna "fuga do mundo para o eu" e afirma "que individuação ocorre no contexto da pluralidade, através do desempenho da ação em um espaço público 'teatral'”. Infelizmente, observa Villa (1996, p. 203), toda a história da teoria política de Platão a Rousseau, se preocupou incessantemente em apontar a pluralidade ou a "teatralidade" como sendo "inimiga da comunidade" ou "como fonte de alienação", mas não se pode esquecer, no entanto, prossegue Villa (2008, p. 352) em outra obra, que "a ideia da comunidade que assombra a tradição ocidental", não é aquela que se baseia na pluralidade humana, mas sim aquela que "repetidamente sacrifica o fato da pluralidade humana no altar da unidade, totalidade, ou singularidade".

Portanto, se Arendt rejeita a ideia da vontade geral de Rousseau, destaca Villa (2008, p. 86), é para defender a "pluralidade humana e a pluralidade de opiniões (individuais)". Mas é importante salientar também, que tal rejeição é ainda mais abrangente, pois ela tem seu fundamento na recusa de Arendt da compreensão filosófica da liberdade como algo localizado em uma vontade subjetiva. Para a autora, liberdade é algo político localizado não no "eu quero", mas no "eu posso", assim, engana-se quem pensa que a liberdade se resume ao "quero" ou ao fazer o que se deseja, e pode dispensar o "posso" entendido por ela como habilidade para agir com os outros no espaço público, no espaço de liberdade. Se desde a época antiga a filosofia "tivesse conhecido um possível conflito entre o que eu posso e o que eu quero", afirma Arendt (1972, p. 207-208), “certamente teria compreendido o fenômeno da liberdade como uma qualidade inerente ao "posso"”. Portanto, para Arendt, o conceito de vontade geral como imaginado por Rousseau, pode ser entendido como uma perpetuação do erro da tradição filosófica de identificar a liberdade com a vontade, ou como observou Molomb'Ebebe (1997, p. 178), a vontade geral como aparece nos escritos de Rousseau, é "uma das derivações da vontade soberana de Epicteto". 


\section{REFERÊNCIAS}

ABBAGNANO, Nicola. Dicionário de filosofia. Tradução Alfredo Bossi. São Paulo: Martins fontes, 2007.

ABREU, Maria Aparecida. Representação em Rousseau e Arendt. Lua Nova, São Paulo, n.72, p. 175-194, 2007.

AMIEL, Anne. A não-filosofia de Hannah Arendt: revolução e julgamento. Tradução João C. S. Duarte. Lisboa: Piaget, 2003.

ARENDT, Hannah. A condição humana. Tradução Roberto Raposo. Rio de janeiro: Forense, 2009a.

ARENDT, Hannah. Da revolução. Tradução Fernando Dídimo Vieira. Brasília: UnB, 1988.

ARENDT, Hannah. A promessa da política. Tradução Pedro Jorgensen Jr. Rio de Janeiro: DIFEL, 2009b.

ARENDT, Hannah. Entre o passado e o futuro. Tradução Mauro Barbosa de Almeida. São Paulo: Perspectiva, 1972.

ARENDT, Hannah. O que é política? Tradução Reinaldo Guarany. Rio de Janeiro: Bertrand Brasil, 2002.

BIRULÉS, Fina. Una herencia sin testamento: Hannah Arendt. Barcelona: Herder, 2007.

CANOVAN, Margaret. Hannah Arendt: a reinterpretation of her political thought.

Cambridge: Cambridge University Press, 1992.

CHARVET, John. The social problem in the philosophy of Rousseau. London: Cambridge University Press, 1974.

DOSSA, Shiraz. The public realm and the public self: the political theory of Hannah Arendt. Waterloo: Wilfrid Laurier University Press, 1989.

ESPOSITO, Roberto. Categorías de lo impolítico. Tradução Roberto Raschella. Buenos Aires: Katz. 2006.

FORTI, Simona. Vida del espíritu y tiempo de La polis: Hannah Arendt entre filosofia y política. Tradução Irene Romera pintor y Miguel Àngel Veja Cernuda. Madrid: Cátedra, 2001.

GARDINER, Rita. Gender, authenticity and leadership: thinking with Arendt. Basingstoke, Hampshire: Palgrave Macmillan, 2015.

HERB, Karlfriedrich. Luz e sombra: o público e o privado em Jean-Jacques Rousseau e Hannah Arendt. Philósophos, v. 7, n.1, p. 75-90, 2002. 
HUISMAN, Denis. Dicionário de obras filosóficas. Tradução Castilho Benedetti. São Paulo: Martins Fontes, 2000.

LA CAZE, Marguerite. Promising and forgiveness. In: HAYDEN, Patrick (ed.). Hannah Arendt: Key concepts. New York: Routledge, 2014.

LAFER, Celso. A reconstrução dos direitos humanos: um diálogo com o pensamento de Hannah Arendt. São Paulo: Companhia das Letras, 1988.

LOBO, María Fátima. Hannah Arendt y la pregunta por la relación entre el pensamiento y la acción. Buenos Aires: Biblos, 2013.

MOLOMB'EBEBE, Munsya. Le paradoxe comme fondement et horizon du politique chez Hannah Arendt. Paris/Bruxelas: DeBoeck/Larcier, 1997.

MÜLLER, Maria Cristina. Comunicação ilimitada: vínculo do cidadão nas comunidades políticas. In: SCHIO, Sônia Maria; KUSKOSKI, Matheus Soares. Hannah Arendt: pluralidade, mundo e política. Porto Alegre: Observatório Gráfico, 2013.

NEMO, Philippe. Rousseau. In: Histoire des idées politiques aux Temps modernes et contemporains. Paris: Presses Universitaires de France, 2002.

NIHAN, Céline. Hannah Arendt: une pensée de la crise. La politique aux prises avec la morale et la religion, Genève: Labor et Fides, 2011.

PAREKH, Serena. Hannah Arendt and the challenge of Modernity: a phenomenology of human rights. New York: Routledge, 2008.

THOMAS, Brook. American literary realism and the failed promise of contract. Berkeley: University of California Press, 1997.

TOPOLSKI, Anya, Arendt, Levinas and a politics of relationality. London: Rowman \& Littlefield International, 2015.

VILLA, Dana. Public freedom. Princeton: Princeton University Press, 2008.

VILLA, Dana. Arendt and Heidegger: the fate of the political. Princeton: Princeton University Press, 1996. 